\title{
Impact of Integrated Arts Therapy: An Intervention Program for Young Female Offenders in Correctional Institution
}

\author{
Kristi Kõiv, Lii Kaudne \\ Institute of Education, University of Tartu, Tartu, Estonia \\ Email: kristi.koiv@ut.ee
}

Received 17 November 2014; revised 15 December 2014; accepted 6 January 2015

Copyright (C) 2015 by authors and Scientific Research Publishing Inc.

This work is licensed under the Creative Commons Attribution International License (CC BY). http://creativecommons.org/licenses/by/4.0/

\section{(c) (i) Open Access}

\begin{abstract}
The aim of the study was to evaluate the impact of program of integrated arts therapy on young female delinquents' who experienced emotional and behavioral problems in a correctional institution. The outlined intervention was introduced as part of a curriculum involving art therapy, drama therapy, music therapy, and dance/movement therapy sessions that were facilitated twice a week during a 5-week period. A quasi-experimental design was used where an intervention group $(N=12)$ and a control group $(N=17)$ members aged $14-17$ years were evaluated at two time points. A self-report version of Strengths and Difficulties Questionnaire (SDQ) and a modified Behavior Checklist (BC) were used prior to and after the intervention to screen for conduct, emotional, peer problems, hyperactivity, and prosocial behavior, and to investigate the frequencies of aggressive, withdrawn and prosocial behavior. There were statistically significant reductions in three of the five emotional and behavioral problems measured by the SDQ, including conduct and emotional problems, an increase of prosocial behavior, and significant differences in two domains measured by the BC: decrease in frequencies of aggressive behavior and increase of prosocial behavior.
\end{abstract}

\section{Keywords}

Integrated Arts Therapy, Young Female Offenders, Quasi-Experimental Design, Behavioral Problems

\section{Introduction}

Arts programs have a long history in offenders' settings-in correctional institutions and in the community, as 
strategies and interventions in rehabilitation (Djurichkovic, 2011). Reviews of the literature (Reynolds et al., 2000; Slayton, D’Archer \& Kaplan, 2010) during three decades support a general positive impact of single-modality arts-based approaches in various settings-schools, outpatient clinics, day treatment centers, residential homes and treatment centers, hospitals, nonclinical setting, and correctional facilities.

Arts therapies offer children, adolescents, adults and elder people therapy primarily through non-verbal means using art forms such as music, art, drama, and dance/movement in the context of psychotherapy, counseling, rehabilitation or treatment (Malchiodi, 2005). Systematic review (Meekums \& Daniel, 2011) about the effectiveness of the arts and arts therapies included studies about five art modalities (art, music, dance-movement, drama, and writing) in the offender context, and the general outcomes reflected overall positive, humanizing, and healing effect. The effectiveness was indicated by improvement of the mental health of adult and adolescent offenders, increase of emotional literacy (management of feelings and capacity to empathize with others), improved behavioral outcomes within the correctional context (reducing rule-breaking and improving relationships), and a decrease of recidivism rates. Also, an economic evaluation of three case studies (one of them among adolescents) has demonstrated how arts and the arts therapy in offender settings is a cost effective way to rehabilitate offenders (Johnson, Keen \& Pritchard, 2011: p. 37).

Although research in offender contexts related to the effectiveness of arts therapies among adults and adolescents has been conducted, there is relatively little evidence about focusing specifically on single-modality artsbased approaches for young offenders. In the qualitative studies of intervention programmes among male (Mazloomian \& Moon, 2007; Persons, 2009; McTaggart, 2010) and female adolescent offenders (Goodkind \& Miller, 2006) have used art therapy, and music therapy among male and female offenders (Rio \& Tenney, 2002). There are two pretest-posttest design studies among institutionalized male juvenile offenders: DeCarlo \& Hockman's (2012) study revealed the outcomes of rap therapy versus traditional group therapy in advancing prosocial behavior across violent offenders, status offenders, and non-offenders; and Johnson (1981) reported significant improvements among music therapy intervention group members on measures of self-concept and a specific change in views of perceiving themselves as having fewer rebellious and distrustful feelings. Hartz and Thick's (2005) quasi-experimental study compared the impact of two art therapy approaches on the self-esteem of female juvenile offenders and both groups showed a significant improvement in self-esteem. A pretest-posttest experimental design with random assignment to groups was used by Tyson (2002) to test the effectiveness of one specific and culture-dependent form of arts-hip-hop therapy, in mixed gender small group context among institutionalized young offenders. The research results showed improvement in peer relations in institution among the intervention group members.

Whereas traditional single modality arts-based approaches emphasize the particular modality, intermodal approaches integrate and embrace all arts modalities (Malchiodi, 2005). Previous qualitative studies including integrated arts approach among female juvenile delinquents have demonstrated that arts programs can be beneficial to both the individual and group situations in the institutional settings (Emerson \& Sherlton, 2001; Lazzari et al., 2005). The improvement of behavioral problems and skills ran also through the quantitative studies (Ezell and Levy, 2003; Clawson \& Coolbaugh, 2001) among mixed gender group context using multiple modalities of arts in institution-based or community-based intervention programs. Namely, as a result of the three year follow up evaluation, Ezell and Levy (2003) concluded that the arts programs through workshops conducted by artists, including poets, musicians, sculptors, videographers, and graphic designers had positive impact on youth behavior both during their incarceration (reduce of rule breaking and misbehavior) and after release (decrease of recidivism rates). In one of the community-based projects, a quasi-experimental design was used to compare the attitudes and behaviors of multimodal art-based (arts, drama, dance, graphics, photograph) program of juvenile offenders and control group members, and results indicate improvements in participants' attitudes toward school, resistance to peer pressure, self-efficacy, skills (e.g. art skill, anger management skills, communication with adults and peers, cooperation, participation), and a decrease in self-reported delinquent behavior during the program (Clawson \& Coolbaugh, 2001).

The existing literature offers little support for the use of integrated arts therapy in correctional institution among juvenile offenders: A main focus on the benefits of mental health and well-being of participants ran through the qualitative studies among males (McMackin et al., 2002) and among females (Mohamad \& Mohamad, 2014) in the group context.

Hence, the research question was raised: Is the integrated arts therapy program effective in decreasing emotional and behavioral problems among female institutionalized young offenders? 
The aim of the study was to evaluate the impact of integrated arts therapy program on young female juvenile delinquents' emotional and behavioral problems in a correctional institution.

\section{Method}

\subsection{Subjects and Research Designs}

The juvenile institution where this research took place was a high security correctional institution for female adolescents in Estonia-a training school; which is the only state correctional facility for female offenders and therefore, no equivalent control group was available within the state. It is unique due to its long-term residential character (residence of two years and more) and distinctive population. All young females were proscribed for residential treatment as a result of committing crimes that ranged from drug possession to robbery, included also serious status offences.

The youth range in age from 14 to 17 years, and all juvenile delinquents $(\mathrm{N}=29)$ from training school fall into an intervention group or a control group. All subjects voluntarily agreed to participate in the research.

A quasi-experimental, intervention-control group pre-test/post-test design was implemented in this study. The experimental group members were volunteers, and a call for volunteers was made to all inmates in the training school. 12 inmates were assigned to the intervention group and the rest of the training school inmates formed a control group. The experimental group members participated in the intervention program-Integrated Arts Therapy Program. All participants attended all therapy sessions and completed the pre- and posttests measurements. The pretest was administrated during the week prior to the program implementation, and the posttest during the week after the program had concluded. The total duration of the study was one and half month—an academic semester.

The control group $(\mathrm{N}=17)$ received no interventions-participants continued their regularly scheduled daily activities and school curriculum. The individuals in the control group participated in the pretest and post test at the same time as the members of the intervention group, and they were given the opportunity to participate in the arts therapies program after the administration of the post-test and collection of the final data.

The age of the participants of the experimental group members ranged from 14 to 16 years (the average age of the intervention group members was 15.56, the standard deviation 0.84); and the age of control group members ranged from 14 to 17 (the average age of the control group members 15.61, the standard deviation 0.93).

\subsection{Integrated Arts Therapy Program}

The implemented intervention runs as an integrated part of school curriculum. For this study, the Integrated Arts Therapy Program within group context was developed integrating all four arts modalities: art therapy, drama therapy, music therapy, and dance/movement therapy layering several art modalities in one session. The intervention addressed the developmental needs of participants— juvenile offenders' problems as identified in practice-based research (Smeijsters et al., 2011) as "core” problems: distortions of self-concept and lack of self-esteem; problems with expressing and regulating emotions; inability to resolve interpersonal problems and build positive relationships with peers. The aims of the integral arts therapy program were: 1) to develop a positive self-concept and self-esteem; 2) to enable participants to express their emotions and to increase emotional regulation skills; and 3) to increase effective interaction in peer relationships promoting prosocial skills development. Art therapy, drama therapy, music therapy and dance/movement therapy (accordingly: $40 \%, 30 \%, 10 \%$, and $20 \%$ ) integrated use fulfilled these three categories of goals. Specifically, art therapy employs two-dimensional and three-dimensional art media to emphasize the change and growth in the area of self and relationship using art materials to gain insight and promote the resolution of difficulties. Prestructured and improvised drama, storytelling, and role-play drama therapy encouraged the expression of emotions and the development of positive self-concept. Music therapy facilitated the interaction and development of insight into the participants' emotional difficulties, relationships and positive self-concept through receptive and active music making, using live, improvised music working with rhythm, pitch, tonality and mood, recreative experiences, composition experiences, receptive experiences. Dance/movement therapy focused on the use of body movement and dance, and the connections among mind, body, and emotion with the aim to increase emotional regulation skills and to develop positive self.

The institution-based intervention program in the educationally oriented context was five weeks long, with sessions occurring twice a week and lasting for 90 min each. The program's total number of sessions-10 for 
two intervention groups was selected in order to fit it within the academic semester time frame. Arts therapies groups were conducted in special activity rooms - in the mental health day-treatment unit in the training school facility.

For this study, two specialists-one of them was the second author of the study, provided sessions to the participants. Both qualified specialist held a masters' degree in education and were also certified in the area of arts therapies during complementary studies. Each practitioner conducted two group sessions per week. Before and during the study, the practitioners met on a weekly basis to discuss the appropriateness of interventions for meeting the established goals as the study progressed; and assessed participants behaviors and group dynamics.

Practitioners took a non-directive, facilitative approach during the sessions: Quite directive in the issues of safety and best interests of the child, but as non directive as possible with regard to the interpretation of the material/art products which arises during the sessions.

\subsection{Session Structure}

The sessions were structured to combine personal exploration and arts-based group work in a safe and confidential atmosphere taking into account the therapeutic group dynamics across the session. Each group session began with interactive warming up activities followed by active-improvisational main activities consisting of components of dance and movement, drama, music, and art therapy methods around one of the main themes fulfilling the aims of the program. The final part of the group session consisted of a discussion or sharing.

In the opening activity, the participants were included in the dance-movement/drama/music/art experience which established a common ground for the main activity. During the first 15 minutes of the session, a main topic or a subtopic (e.g., fear, anger, self-esteem, self-defeating behaviors, barriers to communication, effective communication etc.) was discussed and an exercise related to the topic was introduced. In the main activity section, the participants engaged in sequenced integrated activities of art therapy, music therapy, drama therapy and dance/movement therapy targeting to the "core" problems. The finishing activity of the session included the participants' sharing of their creative experiences and a sense of achievement and mutual supporting.

For each session plan, adaptations and extensions were provided to accommodate individual differences within each group. Integrated arts approach activities were structured and planned but flexible, accepting also spontaneous activities occurring in the secure group context. Although the overall session format remained consistent, the directives varied between the settings and research periods. An example of the session description is summarized in Appendix A.

\subsection{Instruments}

The self-report version of Strengths and Difficulties Questionnaire (SDQ) and modified Behavior Checklist (BC) were used prior to and after the intervention to screen for emotional and behavioral problems (conduct, emotional, peer problems, hyperactivity, and prosocial behavior) and to quantify the frequencies of aggressive, withdrawn and prosocial behavior. The SDQ (Goodman, 1997), as an internationally applied and validated screening questionnaire (SDQ, 2001), which has demonstrated good validity and reliability in different populations (Goodman et al., 1998; Goodman et al., 2000). Questionnaire consists of 25 statements rated on a threepoint scale and divided into five subscales: Conduct Problems, Emotional Problems, Hyperactivity, Peer Problems, and Prosocial Behavior. Each of the items of the SDQ is scored on a 3-point Likert scale with $0=$ not true, 1 = somewhat true or 2 = certainly true, with higher scores indicating greater problems, except for prosocial behavior, where a higher score indicates more positive behavior. All subscale scores are summed to provide standard scores.

The modified BC developed by Ross, Lacey and Parton (1965) consists of three measurement areas as subscales: aggressive behavior, prosocial behavior, and withdrawn behavior. Aggressive-Behavior Scale consists of 25 items (for example items: I interrupt whoever is speaking. I start fighting over nothing), Withdrawn-Behavior Scale consists of (e.g. I become frightened easily. I am slow in making friends) 19 items; and Prosocial-Behavior Scale compose 20 items (e.g. I am considerate of others. I am self-confident) with higher scores reflecting frequent behavior). Items were scored on a four-point Likert scale ranging from $0=$ never to $3=$ very frequently. The sum of each subscale items indicates the descriptive frequency of a particular behavior. The internal consistency of the BC yields average coefficient alpha reliabilities of 0.80 for the Aggressive behavior, 0.78 for prosocial behavior, and 0.79 for the withdrawn behavior scale. 


\section{Results}

In order to identify any change in participants’ emotional and behavioral problems, the SDQ and the BC were administered before and after the program conducted among experimental and control group. The pretest and posttest scores of the SDQ and the CB were compared to test for significant differences before and after the program implementation among two study groups' members using paired sample $t$-tests. The SDQ was used to screen for emotional, conduct and peer problems, hyperactivity and prosocial behavior. The results of $t$-test analysis indicated that in three sub-categories of emotional problems, conduct problems and prosocial behaviors, there were significant differences between the intervention group pretest and posttest scores, and between the intervention group and control group cores after the intervention. There were no significant pre-post differences between two study groups' pre-posttest scores in hyperactivity and peer problems. The pretest-posttest analysis revealed significant changes in outcomes measured by the SDQ between the experimental and control group: decreased conduct problems and emotional problems, as well as improved prosocial behavior among the intervention group members (Table 1 ).

In the three areas of aggressive, prosocial and withdrawn behavior measured by the BC, there were significant differences in aggressive and prosocial behavior, but not in withdrawn behavior between the intervention group pretest and posttest scores, and between the intervention group and control group cores after the intervention. The results of the comparison of the pre- and post-session of the BC results between the experimental and control group showed that there were statistically significant decrease in frequencies of aggressive behavior and increase of prosocial behavior among the intervention group members (Table 2).

\section{Conclusion}

A previous review (Smeijsters et al., 2011) shows that effects of the arts therapies used with young people who have been committed by a juvenile court to an institution can be beneficial to both the individual (reduced aggression, anger, tension, stress, and cognitive distortion and of improvements in impulse control, emotional expression, coping skills) and correctional institution (compliance with rules and social skills). The present study reflects an attempt to specify the impact of integrated arts therapy on emotional and behavioral problems among institutionalized female young offenders. An Integrated Arts Therapy (art, music, drama/movement, and drama) program was developed, applied, and tested using a quasi-experimental research designs in the female juvenile offenders' correctional institution. Also, Wyatt (2002) mention the need to evaluate the benefits of arts therapy among female offenders and our research extends this area in connection with the integration of therapeutic ap-

Table 1. Mean pre- and posttest scores and t-test values among comparison groups' scores on the Strengths and Difficulties Questionnaire (SDQ).

\begin{tabular}{|c|c|c|c|c|c|c|c|c|}
\hline \multirow[b]{2}{*}{$\begin{array}{l}\text { The SDQ } \\
\text { subscale }\end{array}$} & \multicolumn{2}{|c|}{ Experimental group } & \multicolumn{2}{|c|}{ Control group } & \multicolumn{4}{|c|}{$T$-values } \\
\hline & $\begin{array}{c}\text { Pretest } \\
\text { (A) } \\
\mathrm{N}=12\end{array}$ & $\begin{array}{c}\text { Posttest } \\
\text { (B) } \\
\mathrm{N}=12\end{array}$ & $\begin{array}{c}\text { Pretest } \\
\text { (C) } \\
\mathrm{N}=17\end{array}$ & $\begin{array}{c}\text { Posttest } \\
\text { (D) } \\
\mathrm{N}=17\end{array}$ & $\begin{array}{c}\text { A } \\
\text { versus } \\
\text { C }\end{array}$ & $\begin{array}{c}\mathrm{C} \\
\text { versus } \\
\mathrm{D}\end{array}$ & $\begin{array}{c}\text { A } \\
\text { versus } \\
\text { B }\end{array}$ & $\begin{array}{c}\text { B } \\
\text { versus } \\
\text { D }\end{array}$ \\
\hline Prosocial behaviors & 6.64 & 7.55 & 7.05 & 6.81 & 0.69 & 0.47 & $1.71^{*}$ & $1.72^{*}$ \\
\hline Hyperactivity & 4.82 & 4.45 & 5.58 & 5.44 & 1.31 & 0.24 & 0.51 & 1.30 \\
\hline Conduct problems & 3.81 & 2.18 & 4.23 & 4.06 & 1.01 & 0.58 & $2.98^{*}$ & $3.99^{* *}$ \\
\hline Emotional symptoms & 4.72 & 3.36 & 5.12 & 5.00 & 0.44 & 0.13 & $1.74^{*}$ & $1.75^{*}$ \\
\hline Peer problem & 3.82 & 3.36 & 3.71 & 3.50 & 0.16 & 0.33 & 0.73 & 0.24 \\
\hline
\end{tabular}

${ }^{*} p<0.05 ;{ }^{* *} p<0.01$.

Table 2. Mean pre- and posttest scores and t-values among comparison groups on the Behavior Checklist (BC) subscales.

\begin{tabular}{|c|c|c|c|c|c|c|c|c|}
\hline \multirow[b]{2}{*}{$\begin{array}{l}\text { The BC } \\
\text { subscale }\end{array}$} & \multicolumn{2}{|c|}{ Experimental group } & \multicolumn{2}{|c|}{ Control group } & \multicolumn{4}{|c|}{$T$-values } \\
\hline & $\begin{array}{c}\text { Pretest } \\
\text { (A) } \\
\mathrm{N}=12\end{array}$ & $\begin{array}{c}\text { Posttest } \\
\text { (B) } \\
\mathrm{N}=12\end{array}$ & $\begin{array}{c}\text { Pretest } \\
\text { (C) } \\
\mathrm{N}=17\end{array}$ & $\begin{array}{c}\text { Posttest } \\
\text { (D) } \\
\mathrm{N}=17\end{array}$ & $\begin{array}{c}\text { A } \\
\text { versus } \\
\text { C }\end{array}$ & $\begin{array}{c}\text { C } \\
\text { versus } \\
\text { D }\end{array}$ & $\begin{array}{c}\text { A } \\
\text { versus } \\
\text { B }\end{array}$ & $\begin{array}{c}\text { B } \\
\text { versus } \\
\text { D }\end{array}$ \\
\hline Withdrawn behavior & 1.25 & 1.13 & 1.14 & 1.11 & 0.92 & 0.45 & 0.99 & 0.14 \\
\hline Aggressive behavior & 1.03 & 0.52 & 1.17 & 1.07 & 1.43 & 0.51 & $4.79^{* *}$ & $6.28^{* *}$ \\
\hline Prosocial behavior & 1.64 & 1.94 & 1.68 & 1.58 & 0.46 & 0.29 & $1.93^{*}$ & $2.49^{*}$ \\
\hline
\end{tabular}

${ }^{*} p<0.05 ;{ }^{* *} p<0.01$. 
proaches into offenders’ educational settings, supporting previous attempts (Chong \& Kim, 2010).

The present quasi-experimental study revealed statistically significant differences in posttest scores between the control and experimental groups with improvement of prosocial behavior and decrease of aggressive behaviors, conduct problems and emotional problems among intervention group members. The statistical data gathered in this study provided empirical evidence that the integrated arts therapy intervention in a group setting might be effective in reducing emotional and behavioral problems of female juvenile delinquents. It was revealed that female juvenile offenders receiving multi-arts approach integrating art, drama, music and dance/ movement as the group intervention exhibit a change in their behavior with improvement of prosocial behavior and a decrease of their emotional and behavioral problems in the area of aggression, conduct and emotional problems.

The SDQ and CD results supported the assumption that a developed Integrated Arts Therapy Program might be effective to encourage prosocial behavior in the adolescent female offenders in the correctional facility supporting qualitatively revealed benefits of applied integrated arts approaches (Emerson \& Sherlton, 2001; Lazzari et al., 2005) and integrated arts therapies (Mohamad \& Mohamad, 2014) among young female offenders. Also, the increase in prosocial behavior identified through this research links with DeCarlo and Hockman's (2004) study showing benefits of music (rap) program as a tool for advancing prosocial behavior among delinquent and non-delinquent adolescents. We may speculate that the implementation of integrated arts therapy program may cultivate these factors, crucial in raising prosocial behavior, in a way that engages most of this characteristically resistant population-female juvenile delinquents.

The present study also suggests that the institution-based integrated arts therapy program can have an impact on emotional and behavioral problems of female young offenders. First, the results of this study suggested that the implemented multimodal arts therapy intervention was useful in correctional setting to bring about appropriate behavioral changes among the participants during the intervention-a decrease of the frequency of aggressive behavior. Also, Cleveland (1992) found that an improvisational theater program, and Gardstrom (1999) suggest that music therapy intervention, may demonstrate a decrease in violence for the program participantsjuvenile delinquents. Secondly, the present results showed that emotional and conduct problems measured by the SDQ decreased during intervention. A previous qualitative report (Bannister, 2003) in the area of implementation of drama therapy among sexually abused children also showed that parental and teacher opinions on the children's behavior were favorably expressed as they completed the SDQ questionnaire after the intervention. Our positive result in the area of decreasing emotional problems of young female offenders is parallel with data from the literature among adults prisoners (e.g. Ferszt et al., 2004; Gussak, 2004; 2009) indicating that art therapy strongly focuses on emotions and improve the female and male participants' mood. Also, the findings among juvenile delinquents (Clawson \& Coolbaugh, 2001) revealed improvement of anger management skills while using integrated arts approach. The results of the present study in the area of decreasing of conduct behavior of juvenile female offenders are consistent with Ezell and Lewy's (2003) results who found that arts-based programs for juvenile delinquents enabled to increase compliance with institutional rules and decreased misbehavior.

There were some shortcomings in the study, and thus the results of the study should not be generalized to other populations, we emphasize the need for research that would identify principles of an effective integrated arts therapy intervention applicable to both males and females. The second limitation may have been the design of the study - there was no possibility to select participants randomly for the formation of intervention group, but they were voluntarily chosen, and those who volunteered may have been more motivated to participate (Malchiodi, 2003). The strength of randomization is that it creates two groups that are approximately equivalent at the very beginning and it would help to overcome the shortcoming of the present study in which the experimental and control groups show quite different levels (although not significant) on both score forms. The third rigor of this study is the limitation of a relatively short period of intervention to induce intrapersonal and interpersonal changes through the intervention program, as well as the limitation of a relatively small sample size. Following studies will increase the sample size, extend the number of sessions the participants will receive, and broaden the investigation to include not only participants' behavior problems, but also their problems connected with long-term mental health and wellbeing.

This study, notwithstanding its methodological limitations, suggests that the integrated arts therapy (art, drama, music, and dance/movement) in a correctional institution context might be an effective intervention and can lead to at least short-term positive changes in young female offenders' behavior by improving their prosocial 
behavior and decreasing emotional and conduct problems, and frequency of aggressive behavior. In summary, this study identified that developed and implemented integrated arts therapy program was a useful intervention modality for female juvenile offenders in the correctional facility to bring about appropriate behavioral changes among delinquent adolescents' emotional and behavioral functioning.

\section{References}

Bannister, A. (2003). The Effects of Creative Therapies with Children Who Have Been Sexually Abused. Dramatherapy, 25, 1-9. http://dx.doi.org/10.1080/02630672.2003.9689619

Clawson, H. J., \& Coolbaugh, K. (2001). The Youth ARTS Development Project. Juvenile Justice Bulletin. Washington, DC: Office of Juvenile Justice and Delinquency Prevention, US Department of Justice. www.ncjrs.org/html/ojjdp/2001_5_2/contents.html

Cleveland, W. (1992). Art in Other Places: Artists at Work in America’s Community and Social Institutions. Westport, CT: Praeger.

DeCarlo, A., \& Hockman, E. (2012). RAP Therapy: A Group Work Intervention Method for Urban Adolescents. Social Work with Groups, 26, 45-59. http://dx.doi.org/10.1300/J009v26n03_06

Djurichkovic, A. (2011). Art in Prisons: A Literature Review of the Philosophies and Impacts of Visual Arts Programs for Correctional Populations. Salisbury East, QLD: Arts Access Australia.

Emerson, E., \& Shelton, D. (2001). Using Creative Arts to build Coping Skills to Reduce Domestic Violence in the Lives of Female Juvenile Offenders. Issues in Mental Health Nursing, 22, 181-195. http://dx.doi.org/10.1080/016128401750063358

Ezell, M., \& Levy, M. (2003). An Evaluation of an Arts Program for Incarcerated Juvenile Offenders. Journal of Correctional Education, 54, 108-114.

Ferszt, G. G., Hayes, P. M., DeFedele, S., \& Horn, L. (2004). Art Therapy with Incarcerated Women Who Have Experienced the Death of a Loved One. Art Therapy. Journal of the American Art Therapy Association, 21, 191-199. http://dx.doi.org/10.1080/07421656.2004.10129695

Gardstrom, S. C. (1999). Music Exposure and Criminal behavior: Perceptions of Juvenile Offenders. Journal of Music Therapy, 36, 207-221. http://dx.doi.org/10.1093/jmt/36.3.207

Goodkind, S. \& Miller, D. L. (2006) A Widening of the Net of Social Control? “Gender-Specific” Treatment for Young Women in the US Juvenile Justice System. Journal of Progressive Human Services, 17, 45-70.

http://dx.doi.org/10.1300/J059v17n01_04

Goodman, R. (1997). The Strengths and Difficulties Questionnaire: A Research Note. Journal of Child Psychology and Psychiatry, 38, 581-586. http://dx.doi.org/10.1111/j.1469-7610.1997.tb01545.x

Goodman, R., Meltzer, H., \& Bailey, V. (1998). The Strengths and Difficulties Questionnaire: A Pilot Study on the Validity of the Self-Report Version. European Child \&Adolescent Psychiatry, 7, 125-130. http://dx.doi.org/10.1007/s007870050057

Goodman, R., Ford, T., Simmons, H., Gatward, R., \& Meltzer, H. (2000). Using the Strengths and Difficulties Questionnaire (SDQ) to Screen for Child Psychiatric Disorders in a Community Sample. British Journal of Psychiatry, 177, 534-539. http://dx.doi.org/10.1192/bjp.177.6.534

Gussak, D. (2004). Art Therapy with Prison Inmates: A Pilot Study. Arts in Psychotherapy, 31, 245-259. http://dx.doi.org/10.1016/j.aip.2004.06.001

Gussak, D. (2009). Comparing the Effectiveness of Art Therapy on Depression and Locus of Control of Male and Female Inmates. The Arts in Psychotherapy, 36, 202-207. http://dx.doi.org/10.1016/j.aip.2009.02.004

Hartz, L. \& Thick, L. (2005). Art Therapy Strategies to Raise Self-Esteem in Female Juvenile Offenders: A Comparison of Art Psychotherapy and Art as Therapy Approaches. Art Therapy, 22, 70-80.

http://dx.doi.org/10.1080/07421656.2005.10129440

Johnson, E. (1981). The Role of Objective and Concrete Feedback in Self-Concept Treatment of Juvenile Delinquents in Music Therapy. Journal of Music Therapy, 18, 137-147. http://dx.doi.org/10.1093/jmt/18.3.137

Johnson, H., Keen, S., \& Pritchard, D. (2011). Unlocking Value: The Economic Benefit of the Arts in Criminal Justice. New Philanthropy Capital, Report commissioned by Arts Alliance. http://www.artsalliance.org.uk/sites/default/files/UnlockingValue 0.pdf

Lazzari, M. M., Amundson, K. A., \& Jackson, R. L. (2005). We Are More than Jailbirds: An Arts Program for Incarcerated Young Women. Journal of Women \& Social Work, 20, 169-185. http://dx.doi.org/10.1177/0886109905274543

Malchiodi, C. A. (2003). Expressive Arts Therapy and Multimodal Approaches. In C. A. Malchiodi (Ed.), Handbook of Art 
Therapy (pp. 106-119). New York and London: The Guilford Press.

Malchiodi, C. A. (2005). Expressive Therapies: History, Theory, and Practice. In C. A. Malchiodi (Ed.), Expressive Therapies (pp. 1-15). New York and London: The Guilford Press.

Mazloomian, H., \& Moon, B. L. (2007). Images from Purgatory: Art Therapy with Male Adolescent Sexual Abusers. Art Therapy. Journal of the American Art Therapy Association, 24, 16-21. http://dx.doi.org/10.1080/07421656.2007.10129367

McMackin, R. A., Leisen, M. B., Sattler, L., Krinsley, K., \& Riggs, D. S. (2002). Preliminary Development of Trauma Focused Treatment Groups for Incarcerated Juvenile Offenders. Journal of Aggression, Maltreatment and Trauma, 6, 175199. http://dx.doi.org/10.1300/J146v06n01_09

McTaggart, K. (2010). Art Therapy and Young Offenders. Journal of Thai Traditional \& Alternative Medicine, 8, 69-75.

Meekums, B., \& Daniel, J. (2011). Arts with Offenders: A Literature Synthesis. The Arts in Psychotherapy, 38, $229-238$. http://dx.doi.org/10.1016/j.aip.2011.06.003

Mohamad, S. M. A. A.S., \& Mohamad, Z. (2014). The Use of Expressive Arts Therapy in Understanding Psychological Issues of Juvenile Delinquency. Asian Social Science, 10, 144-161. http://dx.doi.org/10.5539/ass.v10n9p144

Ross, A. O., Lacey, H. M., \& Parton, D. A. (1965). The Development of a Behavior Checklist for Boys. Child Development, 36, 1013-1027. http://dx.doi.org/10.2307/1126940

Persons, R. W. (2009). Art Therapy with Serious Juvenile Offenders: A Phenomenological Analysis. International Journal of Offender Therapy and Comparative Criminology, 54, 433-453. http://dx.doi.org/10.1177/0306624X08320208

Reynolds, M. W., Nabors, L., \& Quinlan, A. (2000). The Effectiveness of Art Therapy: Does It Work? Art Therapy, 17, 207213. http://dx.doi.org/10.1080/07421656.2000.10129706

Rio, R. E., \& Tenney, K. S. (2002). Music Therapy for Juvenile Offenders in Residential Treatment. Music Therapy Perspectives, 20, 89-97. http://dx.doi.org/10.1093/mtp/20.2.89

SDQ (Strengths and Difficulties Questionnaire) (2001). What Is the SDQ? http://www.sdqinfo.com/b1.html

Slayton, S. C., D’Archer, J., \& Kaplan, F. (2010). Outcome Studies on the Efficacy of Art Therapy: A Review of Findings. Art Therapy. Journal of the American Art Therapy Association, 27, 108-118. http://dx.doi.org/10.1080/07421656.2010.10129660

Smeijsters, H., Kil, J., Kurstjens, H., Welten, J., \& Willemars, G. (2011). Arts Therapies for Young Offenders in Secure Care-A Practice-Based Research. The Arts in Psychotherapy, 38, 41-51. http://dx.doi.org/10.1016/j.aip.2010.10.005

Tyson, E. H. (2002). Hip-Hop Therapy: An Exploratory Study of a Rap Music Intervention with At-Risk and Delinquent Youth. Journal of Poetry Therapy, 15, 131-144. http://dx.doi.org/10.1023/A:1019795911358 


\section{Appendix A: Sample of Structured Session Description (Session 2)}

Aim of the session: To increase effective interaction in relationships evoking positive emotions.

Warming up activities (a transition activity that is meant to prepare the participants for getting into the session).

- Opening activity_circle time: expression of current thoughts and emotions, expressing emotions through drawing, movement, rhythm and voice, picked items.

Preparing for the art activity (brainstorming and discussing a particular topic or theme with the group).

- Brainstorming and discussing benefits of helping behavior. Developing and agreeing on collective prosocial rules and forming them into creative contract.

Main activities (art making and art sharing).

- Expressing and acknowledging positive emotions through movement, mimics, making music by rhythmical instruments, reflecting emotions through movement and body sculptures.

- Drawing and free-writing positive emotions in close relationships.

- Making so called “mood card” as a mixture of drawing and collage in a group, also adding the names of the emotions to the pictures, expressing two chosen emotions from a collective sculpture of human bodies.

- Writing a letter to someone close and important and designing the envelope according to the content of the letter.

- Preparing and producing improvised drama using the six-part story-making technique, under the theme: The helper.

Ending (closing the art imaginary world of the session and ensuring that the participants are able to walk out of the group safely).

- Making cards with a positive interpersonal message, discussing their content.

- Relaxation and Imaginary Journey.

- A ritual ending with a circle of trust of thumbs. 
Scientific Research Publishing (SCIRP) is one of the largest Open Access journal publishers. It is currently publishing more than 200 open access, online, peer-reviewed journals covering a wide range of academic disciplines. SCIRP serves the worldwide academic communities and contributes to the progress and application of science with its publication.

Other selected journals from SCIRP are listed as below. Submit your manuscript to us via either submit@scirp.org or Online Submission Portal.
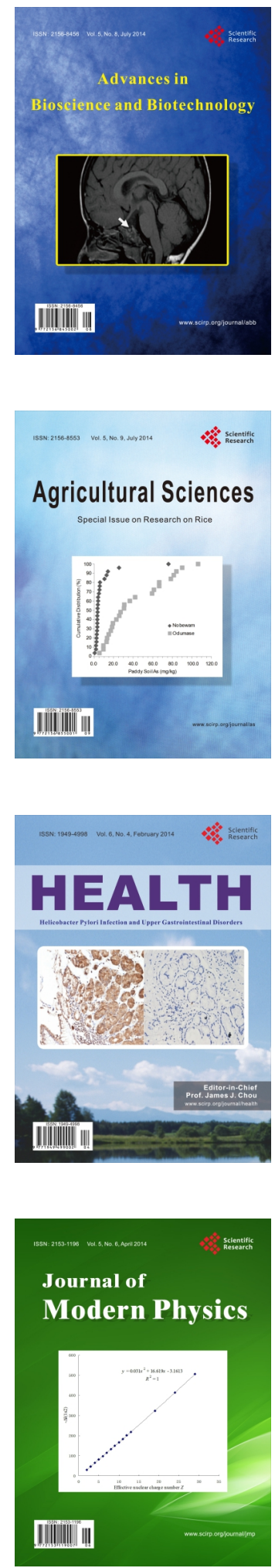
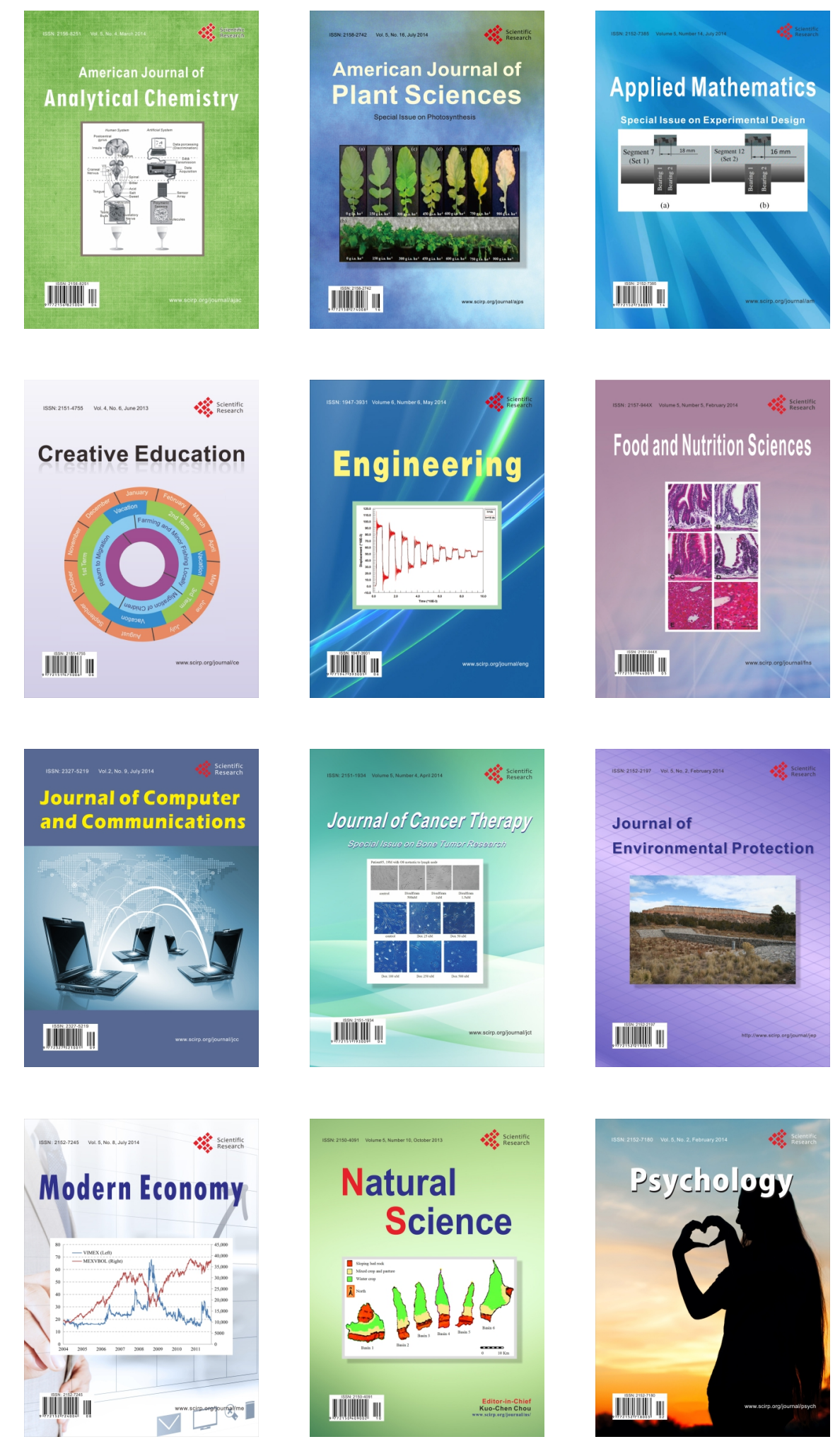